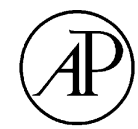

ACADEMIC

PRESS
Available online at www.sciencedirect.com

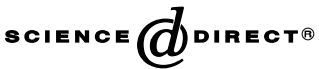

Cognitive Psychology 46 (2003) 229-259
Cognitive

Psychology

www.elsevier.com/locate/cogpsych

\title{
Understanding spatial relations: Flexible infants, lexical adults
}

\author{
Laraine McDonough, ${ }^{\mathrm{a}, *}$ Soonja Choi, ${ }^{\mathrm{b}}$ and Jean M. Mandler ${ }^{\mathrm{c}}$

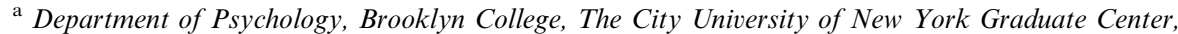 \\ 2900 Bedford Avenue, Brooklyn, NY 11210, USA \\ ${ }^{\mathrm{b}}$ San Diego State University, San Diego, CA, USA \\ ${ }^{\mathrm{c}}$ University of California, San Diego, CA, USA
}

Accepted 17 May 2002

\begin{abstract}
Concepts of containment, support, and degree of fit were investigated using nonverbal, preferential-looking tasks with 9- to 14-month-old infants and adults who were fluent in either English or Korean. Two contrasts were tested: tight containment vs. loose support (grammaticized as 'in' and 'on' in English by spatial prepositions and 'kkita' and 'nohta' in Korean by spatial verbs) and tight containment vs. loose containment (both grammaticized as 'in' in English but separately as 'kkita' and 'nehta' in Korean). Infants categorized both contrasts, suggesting conceptual readiness for learning such spatial semantics in either language. English-speaking adults categorized tight containment vs. loose support, but not tight vs. loose containment. However, Korean-speaking adults were successful at this latter contrast, which is lexicalized in their language. The adult data suggest that some spatial relations that are salient during the preverbal stage become less salient if language does not systematically encode them.
\end{abstract}

(c) 2003 Elsevier Science (USA). All rights reserved.

Keywords: Concept acquisition; Categorization; Language and cognition

\section{Introduction}

A persistent question in psychology concerns the role that language plays in determining thought. This question, which has been with us at least since the writings

\footnotetext{
${ }^{*}$ Corresponding author.
} 
of Edward Sapir and Benjamin Whorf, has had a cyclical history over the years, varying from the assumption of strong influence (e.g., Bloom, 1981) to weak or no influence (e.g., Au, 1992). In between the highs and lows of this cyclical course there have been middle positions, such as that language plays a role in "thinking for speaking" (Slobin, 1996), leaving open the question of the extent to which language affects other kinds of thought as well. Most recently, the cycle has reached a new high point in the estimates of linguistic influence in several crosscultural studies of spatial cognition (Levinson, 1996; Lucy, 1992). The point of view offered by Levinson, for example, is that the spatial frame of reference of a given language influences spatial thought in many tasks, such as recall, recognition, and making inferences (Levinson, 1996).

Hand in hand with differing views of the relation between language and thought have been differing views of the preverbal mind that enable the learning of language, particularly the relational aspects, such as grammatical morphemes and spatial prepositions. Linguists sometimes assumed that there are semantic primitives or conceptual universals (e.g., Bierwisch, 1967) that in various combinations are used to provide the meanings of relational terms in all languages. If these concepts are present preverbally they might help young children learn abstract linguistic categories (Clark, H., 1973). In contrast, many developmental psychologists influenced by Piagetian theory assumed that infants are purely sensorimotor beings, and that at the time that language first begins to be learned have not yet developed a conceptual system. This view entailed the further assumption that language is mapped onto sensorimotor achievements instead. However, empirical studies attempting to correlate language development with scales of sensorimotor development did not provide much support for this idea (Bloom, Lifter, \& Broughton, 1985; Nelson \& Lucariello, 1985).

We assume that whether or not concepts result from sensorimotor activity, some conceptual basis is required to learn language. From the point of view of language acquisition, crosslinguistic studies of early language show that young children everywhere talk about simple events in which animate agents act on inanimate objects (e.g., Brown, 1973; Slobin, 1973, 1985 ). Congruent with this finding, developmental research has shown that preverbal concepts of animacy, inanimacy, and agency begin to be formulated in the first year of life, as well as concepts of the events in which objects take part (Johnson, Slaughter, \& Carey, 1998; Legerstee, 1992; Mandler \& McDonough, 1996; McDonough \& Mandler, 1998; Spelke, Phillips, \& Woodward, 1995). These abstract characterizations of events provide a conceptual base onto which simple sentence structure can be mapped (Mandler, 1996).

A good deal of research has begun to flesh out the concepts preverbal infants have formed about animate and inanimate objects (e.g., Mandler \& McDonough, 1996, 2000), but the concepts onto which spatial language is mapped have remained more speculative. Perhaps the best known approach was that of the Clarks (Clark, E., 1973; Clark, H., 1973), who assumed that there are cognitive universals that account not only for commonalities in spatial terms across various languages but also for the easy acquisition of simple spatial prepositions. Examples of universal primitives that have been suggested include containment, support, contact, opening and closing, 
horizontality, verticality, and path (e.g., Bloom et al., 1985; Clark, E., 1973; Nelson, 1974; Sinha, Thorseng, Hayashi, \& Plunkett, 1994; Talmy, 1985). Many of these are similar to the image schemas underlying language understanding discussed by cognitive linguists (e.g., Lakoff, 1987; Johnson, 1987) and proposed by Mandler (1992) as developing early in infancy. Such conceptual primitives, whether innate or learned, would help constrain the possible meanings of spatial terms, making language learning easier for the child.

Much of the relevant early research was conducted in English, but as crosscultural data on acquisition became more frequent it became apparent that across languages children learn spatial relational terms of widely diffferent forms equally easily. This finding suggested that the notion of a small set of spatial primitives might not be a plausible way to explain acquisition. Bowerman $(1989,1996 \mathrm{a})$ and Bowerman and Choi (2001) discussed some of the highly variable ways of expressing containment and support that various languages use, from the semantically rather general "in" and "on" of English to the elaborate system of body-part metaphors found in Mixtec or the obligatory requirement when talking about containment in Tzeltal to choose the spatial term that specifies the shape and orientation of the container (Brown, 1994). As they pointed out, children in the languages that have been studied pick up on varying semantic categories quite easily. For example, Choi and Bowerman (1991) described how Korean spatial morphemes specify loose- or tight-fitting relations crosscutting the categories of containment and support, and showed that young Korean children encode this variable when talking about spatial relations. In Korean, the spatial verb "kkita" means 'fit together tightly or interlock', regardless of whether something is contained or supported. For example, putting books into book covers, putting pegs tightly into holes, putting rings tightly on poles and putting lego blocks together are all good instances of "kkita" in Korean. Korean does not have a verb that has the same semantic content as that of "in" nor does English have a particle/preposition with a meaning comparable to that of "kkita."

Choi, McDonough, Bowerman, and Mandler (1999) studied the onset of comprehension of "kkita" in Korean and "put' in" in English, and found that at the earliest age at which reliable comprehension of such terms was shown (18 months) infants were already sensitive to the different aspects expressed by spatial morphemes in the two languages (see below for more detail on the Choi et al. experiment). Bowerman and Choi (Bowerman, 1996b; Bowerman \& Choi, 2001) concluded that the language being learned is in some sense teaching children how to conceptualize spatial relations.

This discussion suggests a chicken and egg problem. On the one hand it is not clear how it would be possible to learn any spatial terms without some conceptual base on which to map the sounds of one's native tongue. On the other hand, how can it happen that the earliest comprehension of spatial terms already shows language-specific influences if language were not influencing the infant's conceptions of space? One possible answer would be that preverbal infants have already learned a larger or perhaps different set of spatial concepts than is usually credited to them. Perhaps infants have not only already learned concepts of containment and support, but also concepts of tight and loose fitting, so that when Korean infants, for example, hear the word "kkita," 
('put together tightly or interlock') and "nehta," ('put in, around or together loosely'), they are as prepared to understand these terms as infants learning English are to understand the terms "in" and "on." In this view, language is not "teaching" these concepts, but instead is packaging existing concepts semantically in different ways, each of which is roughly easy to learn. ${ }^{1}$ Thus, different languages create different semantics from a common preverbal conceptual base, enabling infants to learn language-specific semantics.

The notion of semantic primitives helping with the task of language acquisition fell into disrepute because of an apparent lack of empirical support and because of the theory-laden descriptions attached to them (see Bowerman, 1996b and Carey, 1982, for discussion). One criticism was that the primitives used to distinguish various spatial categories (such as long versus tall versus wide) are too abstract and sophisticated to be plausible for preverbal children to know and so it is not clear how they would help constrain initial hypotheses about spatial word meaning. It was also suggested that there would need to be a very large number of primitives to accommodate learning all language-specific spatial concepts (Bowerman, 1996b). However, children acquire spatial terminology only gradually, with differences among such dimensional terms as tall versus wide being relatively late acquisitions. It does not seem necessary for all spatial notions to be available to infants for them to begin to learn how many common spatial notions are expressed in their native tongue. There may be a universal set of preverbal distinctions acquired by all infants in their experience with the world that can be used to compile the most common and early learned linguistic spatial categories found in different languages. Perhaps the search for conceptual primitives was abandoned too early. Given the recent research in cognitive development showing more conceptual understanding in infancy than once thought possible, it seems timely to investigate the various components that are implicated in linguistic spatial categories to see if preverbal children are already sensitive to them.

There is by now a good deal of data on the early development of concepts related to containment and support in the first year of life. For support, Baillargeon and her colleagues describe a learning sequence in which first a qualitative distinction between support and nonsupport is made, followed by gradual learning of quantitative details, such as how much overlap between objects is needed if one is to support the other (Baillargeon, 1994). For containment, there are fewer systematic developmental data in infancy, but it is known that by 5.5 months infants know that containers must have bottoms (Baillargeon, 1995), and by 8.5 months they take into account the width and compressibility of an object when determining whether it can be put into a container (Aguiar \& Baillargeon, 1998). The latter finding in particular suggests a fairly sophisticated understanding of containment. As for tightness vs looseness, to our knowledge there is no work other than that presented here that has investigated these concepts in infancy.

\footnotetext{
${ }^{1}$ This would not necessarily be the case for all languages. Some distinctions that languages make are more difficult for young children, such as the Dutch preposition "aan" meaning roughly 'supported by attachment' (Bowerman, 1996a, 1996b).
} 
The present research asks whether these concepts of containment and support that preverbal infants have already formed (and perhaps degree of fit as well) are sufficiently abstract and context-free to account for the understanding of the basic spatial vocabulary of either Korean or English that begins around 18 months of age (Choi et al., 1999). Secondarily, it asks whether after learning Korean or English and using these differing spatial terms for many years, adult Korean and English speakers differ in nonverbal spatial categorization and in one kind of spatial thought.

In our previous research we investigated children's comprehension of two spatial terms: the English word "in" and the Korean word "kkita" (Choi et al., 1999). We used a preferential looking test in which two scenes were shown simultaneously and were accompanied by an audio recording which described one but not the other scene. For example, one scene showed a book placed on top of another book and the other scene showed a book placed into a tight-fitting cover. The English audio directed the child with instructions such as "Look! Where is she putting it in?." The Korean audio directed the child with instructions (in Korean; i.e., "Eti-ey kkie" 'where-at tight-fitting') that would translate to "Look! Where is (she) tight-fitting (it)?" In this situation, both the English and Korean children should look at the same scene, namely putting a book in a matching book cover, since the relation depicts both containment and tight fit (see Fig. 1). Another pair of scenes showed a ring dropped into a large basket and a ring placed tightly onto a pole. Using the same audio, English children should look to the ring tossed into the basket (i.e., containment) whereas Korean children should look to the ring placed tightly on the pole

\section{Spatial categorization in English and Korean: IN/ON vs. KKITA}

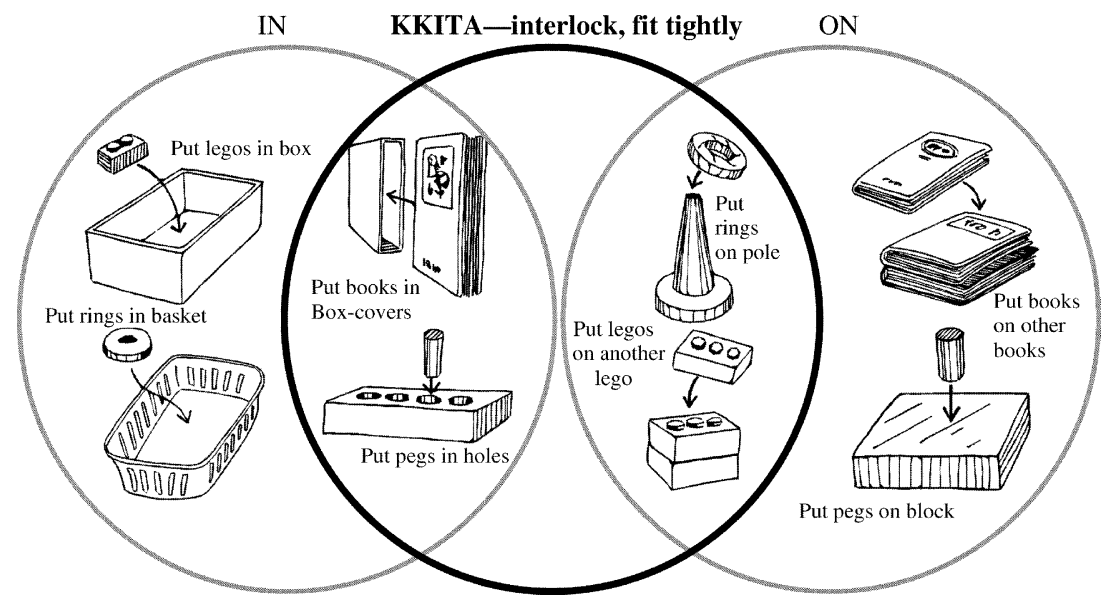

Fig. 1. An example is shown of the manner in which spatial relations are categorized in English and Korean. The scenes in the left circle show containment relations and the scenes in the right circle show support relations. Tight-fitting relations are shown in the center circle that intersects both containment and support relations. 
(i.e., tight fit). This technique was effective in showing that by 18 months of age, children will look to the scene described in their language, indicating their comprehension of the way the language they are learning carves up spatial relations. That is, as Fig. 1 shows, 18-month-old Korean children understood 'books in book covers' and 'rings on poles' to instantiate a tight-fitting relation, whereas 18-month-old Englishlearning children understood that 'books in book covers' and 'rings in basket' instantiate containment.

The present studies again used a preferential-looking technique to study the development of concepts of containment, support, and degree of fit in preverbal infants. We studied 9- to 14-month-olds and familiarized them to varied instances of a spatial relation. Then we tested their preferential looking by giving them two test trials in which one scene showed a novel instance of the familiarized relation and the other scene showed a novel relation. We used a wide variety of objects that differed on many dimensions (shape, size, color, and texture) to make sure that any categorical responses would be based on spatial relations rather than on physical similarity or similar taxonomic relations among objects. We were particularly interested to discover whether infants in this age range have developed spatial concepts abstract enough to account for the wide range of instances that 18-month-olds include when they begin to understand the relevant relational terms. Because they apply their newly learned words even to new instances they have not seen before, it seems likely that an abstract understanding is required.

It also seems likely that such understanding develops over the course of the first year. For example, Quinn (1999; Quinn, Cummins, Kase, Martin, \& Weissman, 1996) found that 3-month-olds could categorize above and below relations involving a single figure (such as a dot or geometric drawing) vis a vis a line but not until several months later could infants categorize these relations when more than one figure was used. The work of Baillargeon and her colleagues also implicates major developmental changes during the first year in understanding containment and support. However, their experiments also used a limited range of stimuli, which made the spatial changes highly salient (Baillargeon, 1994, 1995). One cannot be certain from this work whether infants in the first year can categorize containment and support relations when a wide range of objects is presented.

In the present experiments, we also tested adults who are either fluent in English or Korean by giving them the same preferential looking tasks we gave to infants. We do not in fact know if even adults will abstract a common spatial relation from a series of otherwise unrelated events. Therefore, we wanted to see if adults show the same looking preferences as infants and, if so, whether they are aware of the relational distinctions being tested. To test their awareness of the category differences, we gave them an oddity task after which we asked them to explain the bases for their selections. If adults are influenced by language in their construal of events, as suggested by Whorf (1956), then evidence should be found in the adults' verbal descriptions of the tasks. More specifically, as recent studies have suggested (i.e., Levinson, 1996; Pederson et al., 1998), it is possible that those aspects of space that are semantically relevant to a speaker's language may become more salient over time and more available as a basis for nonlinguistic spatial categorization. 


\section{Experiment 1}

To begin our investigation of preverbal spatial categories we needed to see if the preferential looking technique would work, so we used a distinction that seemed as salient as possible: tight-fitting containment versus loose-fitting support. In English and Korean, these two relations are subsets of two distinct semantic categories in each language: "in" and "on" in English denoting containment and support respectively (but not tight or loose fit), and "kkita" and "nohta" in Korean denoting tight fit (regardless of containment or support) and loose support respectively.

In addition to testing infants, we also tested adults. We first gave each adult the same preferential looking task we gave to infants by simply asking them to watch the films while we videotaped their looking patterns. Then we asked them to make a selection on an oddity task. In this task, three relations from the familiarization trials along with one novel relation from a test trial were demonstrated by the experimenter using the same objects shown in the looking task. After a selection was made, we asked the participant to explain her or his selection. We know that adults understand the differences between containment and support as well as between tight and loose, but it was not clear to us that they would focus on the spatial relations in a task that uses many highly varied objects and that has no explicit instructions. Adults are not typically asked to reason about spatial relations and often find it difficult to work with them even when instructed to do so (e.g., Emmorey, 1996; Levinson, 1996).

\subsection{Method}

\subsubsection{Participants}

Three age groups of infants were tested: 9-month-olds (mean age: 9 months, 12 days; range: 9 months, 1 day to 9 months, 25 days), 11-month-olds (mean age: 11 months, 14 days; range: 11 months, 1 day to 11 months, 26 days), and 14-montholds (mean age: 14 months, 14 days; range: 14 months, 0 days to 14 months, 29 days). Fourteen participants in each age group are included in the final analysis. Participants were selected from an existing subject pool. All were being raised in monolingual English-speaking environments. An additional 9 infants were tested but were eliminated from the final data set due to fussiness (1), side-bias (6), or coder agreement not at criterion (2). Infants were given a small gift for participation.

A group of 32 undergraduate students also participated in the experiment. All participants were fluent in English. After testing, we asked them if they were fluent in other languages. Three were, but their other languages made the same semantic distinction (such as "in" vs. "on") tested in the present experiment.

\subsubsection{Procedure}

To assess categorization of spatial relations in both the infants and adults, we used a familiarization technique along with a preferential looking test. During the 
familiarization trials, 6 videotaped scenes showing the enactment of a particular relation (e.g., tight-fitting containment) were presented in pairs on two screens, one scene to the right of the participant and the other presented to the left of the participant. The scenes were professionally filmed and edited so that they ran simultaneously on two videotapes - one for each monitor-with trial duration and intervals perfectly synchronized. After the three pairs of scenes were shown, the same paired scenes were then shown again in the same order but on opposite screens. For example, the scene shown on the left screen on the first trial was then shown on the right screen on the fourth trial. The dependent measure for the familiarization trials was the mean amount of time looking at the two scenes during the first 3 and the last 3 familiarization trials. This provided a measure of how long the familiarization trials were attended to and if looking decreased from the first to the second presentation of the scenes. The data were also examined during the familiarization trials to evaluate any side biases, operationalized as looking at the same side but not the other during 4 of the 6 familiarization trials. The familiarization scenes were accompanied by an excerpt of the musical score "Oh! Mathilda!' Half the participants were familiarized with tight-fitting containment relations, the remaining half were familiarized with loose-fitting support relations.

The test trials were presented immediately following the familiarization trials. All participants saw the same two pairs of test trials. Within each test pair, one scene showed the same relation depicted in the familiarization trials and the other scene showed the contrasting/novel relation. Half the participants were tested so that the novel relation in the first test trial was presented on the right monitor and the novel relation in the second test trial was presented on the left monitor. The remaining half were shown the novel relation on the left and then on the right monitor for the first and second test trials respectively. The test scenes were accompanied by an excerpt of "The Mexican Hat Dance." The dependent measure for the test trials was the amount of time looking at each scene.

It was predicted that if the participant recognized the contrast between the familiarization trials and the novel test scenes, that this recognition would be reflected in their preference for looking at one scene over the other. Previous research that uses preferential looking measures shows that participants usually prefer to look at the novel test scene; however, this research is typically accompanied by a requirement that infants habituate to the familiarization trials. Since habituation was not required in our task, we considered the possibility that preferences might be found for the familiar test scenes. This consideration was made in light of research by Hunter, Ames, and Koopman (1983), who showed that infants prefer novel scenes when simple stimuli are used during familiarization but will prefer familiar scenes when highly complex stimuli are used. Based on the findings that spatial relations can be difficult to process, even for adults (see Levinson, 1996), we predicted that if participants are continuing to process the familiarization stimuli during the test trials, then they should show a preference for the familiar test scene. However, if they have fully processed the relations shown in the familiarization trials, then they should be more motivated to look longer at the novel scene. 


\subsubsection{Stimuli}

In each videotaped scene, a hand was shown demonstrating a relation (either tight-fitting containment or loose-fitting support) three times in succession. As can be seen in the first table in the Appendix A, the objects used in the demonstrations differed in shape, texture, color, size, and number. For example, in the first familiarization trial listed in the Appendix A, 3 wooden pegs were placed one at a time atop a rectangular wooden board in the left scene whereas three geometric blocks were placed atop 3 different wooden poles in a one-to-one correspondence in the right scene. For the test trials, the objects used were new; however, the objects used to demonstrate the novel and familiar relation were similar to (and sometimes identical to) each other. We chose the objects for the test scenes to be as similar as possible to avoid any perceptual biases participants might have for one set of objects over another. As can be seen in Table 1, in the first test trial, pastel colored foam letters (S, E, T) were placed in an upright position on top of a table in the right scene, whereas in the left scene each of the three letters was placed firmly and tightly into a corresponding letter shaped cut out section in each of three mats. Since all participants were given the same test trials, the relation that was considered novel for the group familiarized with one relation was considered familiar for the group familiarized with the opposite relation. For example, the test scene in which letters were placed tightly into various colored mats would be novel to those familiarized with loose-fitting support relations but would be familiar to those familiarized with tight-fitting containment relations. Familiarization and test scenes were each $8 \mathrm{~s}$ in duration. Intervals between each of the familiarization and test trials were $2 \mathrm{~s}$ long.

\subsubsection{Apparatus}

Our lab setup was adapted from Naigles (1990). The infant sat on a parent's lap facing two $20^{\prime \prime}$ video monitors, which were mounted side by side, $15^{\prime \prime}$ apart. The parent wore opaque glasses during the session so that she or he could not inadvertently cue the infant to look longer at one scene than another. The adult participants were also tested individually and were seated in the same chair used by the parents. Between the monitors was a camera for videotaping eye movements above which was a speaker for playing music during the trials. The monitors, camera and speaker were surrounded with black paneling. Beneath the speaker, surrounding the camera lens, was a ring of flickering red lights, which was activated between trials to draw the participant's attention to the center. The videotape of looking behavior was coded and analyzed off line. The video and audio presentation, lights and video camera were controlled by a computer located behind the panel.

The adult participants were given little in the way of instructions about the task. They were told that two videotapes would be shown simultaneously and they were to look at them until the experimenter told them that no more videos would be shown. Their eye movements were videotaped for later coding. Participants were not told the purpose of the videotapes nor what they should be looking for. We kept the instructions as simple and as uninformative as possible. 


\subsubsection{Coding and reliability for the preferential looking task in each of the experiments}

The video of each infant's (or adult's) looking behaviors was coded off line using a button-press box indicating looking to the left or right monitor, to the center between the monitors or away from the monitors. Coders were blind as to the condition in which each participant was tested. Agreement was based on the test trial data. Reliability was considered acceptable if both coders agreed on which scene was looked at longer on every test trial (100\% agreement) and discrepancies did not exceed $0.5 \mathrm{~s}$ per scene. The first coder's measures on the looking times were then used for the analyses.

\subsubsection{Oddity task given to adult participants}

After the looking task, the adult participant was led into a separate experimental room where a subset of the objects shown during the looking task were laid out on a table. Three sets of items were from the familiarization trials (shown in the Appendix A; e.g., a book and a form-fitting cover, a lego person and car, a cork and bottle were all used to demonstrate the tight-containment relation), the fourth set (i.e., the letter 'S' and a bowl used to demonstrate the loose-support relation) was from one of the test trials. The familiarization items were used to demonstrate the spatial relation seen during the familiarization trials. The test items were used to demonstrate the spatial relation that was novel relative to the familiarization trials. The four relations were demonstrated in random order one at a time. The experimenter then asked, "Which display does not belong with the other three?" The experimenter was careful not to ask for the odd object group or odd relation demonstrated - she simply asked for what did not belong with the other three. Once a choice was made, the participant was asked to explain her/his selection.

\subsection{Results}

\subsubsection{Familiarization trials}

The infant data were first analyzed to determine if looking time decreased from the first 3 familiarization trials in which the six scenes were presented for the first time to the second 3 familiarization trials in which the scenes were shown again. The dependent measure was the mean looking time to both scenes (Maximum $=8 \mathrm{~s}$ ). A mixed-design analysis of variance for repeated measures was conducted with Trial (first 3-, last 3-familiarization trials) as the within-subjects factor and Age (9-, 11-, 14-months), Gender, and Familiarization category (tight containment, loose support) as the between-subjects factors. The results showed no significant effects or interactions. Although infants tended to look longer during the first 3 familiarization trials $(M=5.45 \mathrm{~s} ; S E=0.19)$ than the last 3 familiarization trials $(M=4.98 \mathrm{~s}$; $S E=0.19)$, this difference was not significant, $F(1,30)=2.46, p=.13$. The lack of habituation to the stimuli is not an uncommon finding when varied and interesting scenes are used.

The same analysis, with the exception of the age factor, was conducted on the adult data. Again, no significant effects or interactions were found. Participants looked about the same amount of time during the first 3 familiarization trials 
$(M=7.16 \mathrm{~s} ; S E=.006)$ as during the second 3 familiarization trials $(M=7.17 \mathrm{~s}$; $S E=.005), F(1,28)=0.03, p=0.88$. Note that looking time approached ceiling levels $($ Maximum $=8 \mathrm{~s})$. This finding indicates that the participants followed the instructions to look at the scenes.

\subsubsection{Test trials}

Next, the infant data were analyzed for preferences during the test trials. If infants were able to analyze the common spatial relation demonstrated on the various objects during the familiarization scenes, then a reliable preference for one of the test scenes (either the novel or familiar) should be found. In this analysis, the between-subject factors were Age, Gender, and Familiarization category and the within-subject factors were Test trial (first test pair, second test pair) and Scene (novel, familiar). Huhyn-Feldt corrections were applied for the within-subject factors in this and the following experiments. Where applicable, post hoc one-way analyses of variance were conducted to determine the locus of interactions (Keppel, 1982).

The results revealed an interaction involving Scene and Age, $F(2,30)=5.61$, $p<.01$. As can be seen in Fig. 2, the 9-month-olds tended to look longer at the familiar $(M=3.06 \mathrm{~s} ; S E=0.29)$ than the novel scenes $(M=2.10 \mathrm{~s} ; S E=0.29)$, $F(1,13)=3.78, p=.07$. The 14-month-olds showed the opposite preference by looking significantly longer at the novel $(M=3.49 \mathrm{~s} ; S E=0.26)$ than the familiar scene $(M=2.06 \mathrm{~s} ; S E=0.37), F(1,13)=7.16, p=.02$. The 11-month-olds showed no reliable preferences in their looking at the novel $(M=2.96 \mathrm{~s} ; S E=0.44)$ and

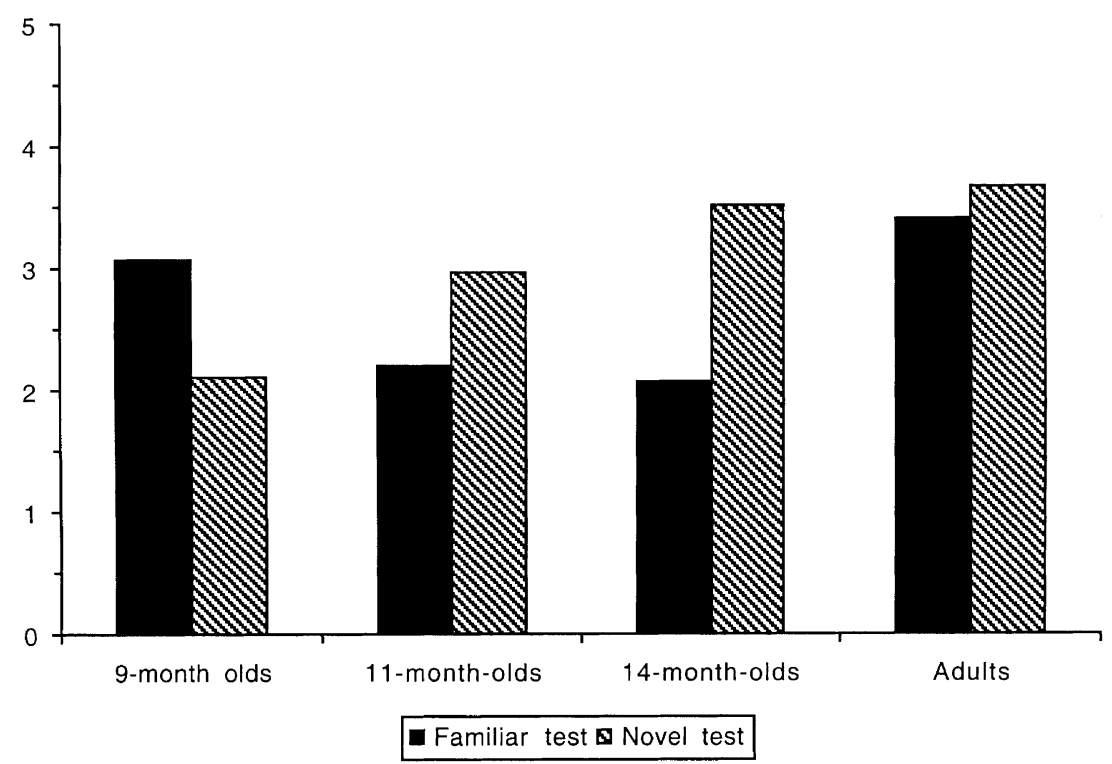

Fig. 2. The results of Experiment 1 showing the interaction in the infant data involving Scene and Age. The adult data are also shown to the right of the infant data. 
the familiar scenes $(M=2.20 \mathrm{~s} ; S E=0.26), F(1,13)=1.64, p=.22$. No further effects or interactions were found.

These results indicate a developmental shift from a preference for the familiar at 9 months to a preference for the novel at 14 months. One interpretation of the youngest infants' preference for a familiar scene is that they were continuing to process the familiarization stimuli. On this interpretation, the infants were in a confirmatory response mode, looking to find more examples of the same kind of thing (in this case, the same spatial relation). However, the oldest group showed an opposite preference, one to the novel test scene. Hence, one explanation for this developmental progression is that the younger infants were continuing to process the familiarization category whereas the older infants had completed processing the familiarization category, leading them to shift their attention to the novel relation.

We now turn to the question of whether adults also show looking preferences indicating a categorical response reflecting the distinction between tight containment and loose support. A mixed-design repeated measures ANOVA was conducted with Gender and Familiarization category as between-subjects measures and Test trial (first test trial, second test trial) and Scene (novel, familiar) as within-subjects measures. The results showed a main effect for Scene indicating that participants looked significantly longer at the novel $(M=3.66 \mathrm{~s} ; S E=0.12)$ than the familiar scenes $(M=3.39 \mathrm{~s} ; S E=0.13), F(1,14)=6.80, p<.05$. A closer examination of the data indicated that longer looking to the novel scene was more evident on the first than the second test trial (first test trial: Novel $M=3.85 \mathrm{~s} ; S E=0.16$; Familiar $M=3.23 \mathrm{~s} ; S E=0.14$; second test trial: Novel $M=3.54 \mathrm{~s} ; S E=0.23$; Familiar $M=3.46 \mathrm{~s} ; S E=0.20)$.

\subsubsection{Proportion of participants who looked longer at the novel scenes}

Consistent with the above results on the infant data showing that looking time increased to the novel scenes with age, the proportion of infants who showed this pattern also increased with age. Whereas only $29 \%$ of the 9 -month-olds looked longer at the novel test scenes, $58 \%$ of the 11 -month-olds and $79 \%$ of the 14 -month-olds looked longer at the novel than the familiar test scenes. The number of 14-montholds who looked longer at the novel scenes was greater than chance expectation, $\chi^{2}(1)=4.57, p<.05$.

Twenty-two of the 32 adult participants $(69 \%)$ looked longer at the novel than the familiar test scene on the first test trial, $\chi^{2}(1)=4.50, p<.05$. Only $15(46 \%)$ participants looked longer at the novel than the familiar test scene on the second test trial. After the exposure to the first novel scene in the first test trial, the second "novel" scene shown in the second test trial was less likely to be seen as such.

\subsubsection{Oddity task}

Of the adult participants, 25 (78\%) correctly identified which of the four relations demonstrated by the experimenter was the one that did not belong with the other three. All of them correctly described the odd relation as the distinction between containment and support by using the terms "in," "on," "inside," "on top of," or "contains." No one mentioned the distinction in terms of the kind of fit ('tight' vs. 'loose'). 


\subsection{Discussion}

The results of the preferential looking task show that both preverbal infants and English-speaking adults can abstract a common spatial relation across a wide variety of objects. These findings are impressive for two reasons. First, unlike the traditional view that infants learn about the world in context-specific ways, the results demonstrate that infants can abstract a common relational element (e.g., a preverbal rendering of something like 'put one object into another') even when the objects differ on several dimensions. Second, adults also demonstrate preferential looking on the basis of these abstract categories even when no instructions are given to them to do so. This finding may not seem surprising since we know that the adult participants in our study distinguish containment and support. We might also expect all the adults to select the correct item on the oddity task. However, previous research showing that space can be analyzed in a number of different ways (e.g., deictic, relative, absolute, or intrinsic; Levelt, 1996; Levinson, 1996) indicates that spatial relations are not as simple nor as straightforward as sometimes thought. Even when given explicit instructions to make a choice on an oddity task, some adults still did not focus on the spatial relations. Incorrect selections were made, some with the reason that a particular property of one of the objects differed from the others (e.g., "this one is transparent whereas the others are opaque"). Interestingly, none of the adults mentioned that the relations differed in terms of "tight" and "loose." These findings suggest that the most salient construal of a scene is influenced by the way it is most commonly described in language.

\section{Experiment 2}

The results from Experiment 1 indicated that the preferential looking technique is a viable method for use with 9 to 14 -month-olds even when the contrasts under study are abstract spatial relations, and so more detailed crosslinguistically meaningful studies could begin. In Experiment 2, we tested a contrast between tight-fitting containment and loose-fitting containment. This contrast is saliently marked in Korean by the terms 'kkita' and 'nehta' (although neither are strictly limited to containment relations). In English, these scenes can be construed as more subtle variations on containment ('in'). English does have words 'tight' and 'loose' but they are not grammaticized elements as the spatial particles 'in' and 'on' are, and thus are not so frequently used. In Experiment 2, we again tested preverbal infants who were being raised in monolingual English-speaking environments and English-speaking adults. In line with the position that infants develop a set of preverbal concepts that they make use of when learning language (Mandler, 1996), we predicted that the preverbal infants would analyze and show categorization of the tight- and loose-containment relations.

Predictions of the adult data were more difficult to make. If language influences adults' construal of the filmed events (as it seemed to do in Experiment 1 in that none of the adults mentioned the difference between tight and loose) then 
English-speaking adults may not categorize the scenes but consider them as variants within a common containment category based on the lexical item "in." Alternatively, they could evoke their semantic knowledge of the lexical items "tight" and "loose" and categorize the scenes accordingly while ignoring containment. On the other hand, it is also possible that adults do not use a linguistic construal during the preferential looking task at all; they may look longer at the novel relation without knowing why. In this case, their longer looking may be guided by implicit processes and they should do poorly in their explanation of their selection on the oddity task. This prediction is based on the explanations from Experiment 1 in which none of the participants mentioned degree of fit even though the scenes could be easily categorized using this strategy.

\subsection{Method}

\subsubsection{Participants}

Eight infants at each of the three ages (9-, 11-, and 14-months) were tested. The mean age of the 9-month-olds was 9 months, 12 days (range: 9 months, 3 days to 9 months, 23 days); the mean age of the 11-month-olds was 11 months, 19 days (range: 11 months, 1 day to 11 months, 29 days); and the mean age of the 14-month-olds was 14 months, 15 days range (14 months, 4 days to 14 months, 28 days). An equal number of males and females were tested in each age group. Participants were selected from the same source as Experiment 1. Each infant was given a small toy for participation. An additional 4 infants were tested but not included in the final analyses: 3 for a side bias in their looking, and 1 because reliability could not be obtained between coders for this infant.

As in Experiment 1, 32 undergraduate students, all fluent in English, participated in the experiment for course credit. A few of these students were bi- or multi-lingual. One participant was excluded from the study because Korean was his first language and he spoke it on a daily basis. Adults were tested in the same manner with the same verbal instructions as in Experiment 1.

\subsubsection{Procedure}

The same procedure was used as in Experiment 1 with the exception that the contrast tested was between tight-fitting containment and loose-fitting containment relations. Six familiarization trials were shown (see Appendix A) immediately followed by two test trials. In Fig. 3 is a drawing of the test trials. For the participants who were familiarized with tight-fitting containment, the letters placed in bowls in the left scene of test trial 1 and the sticks placed in the various boxes in the right scene of test trial 2 would be the novel scenes. For the participants who were familiarized with loose-fitting containment, the letters placed tightly in the mats in the right scene of test trial 1 and the sticks placed tightly in the holes of the various shapes in the left scene of test trial 2 would be the novel scenes. As in Experiment 1, the test trials were designed so that the objects were not the same as any of those used in the familiarization trials. Yet, the figure objects within the paired test trials were identical in order to avoid any preferences infants might have for one object set over 
Test Scenes

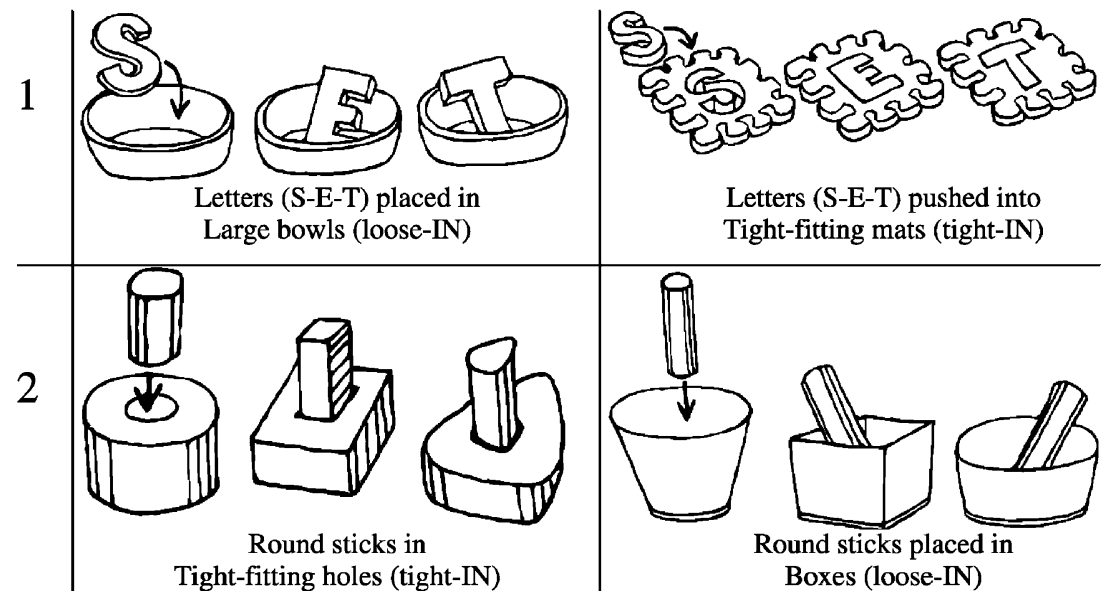

Fig. 3. The stimuli used for the two test trials in Experiments 2 and 3.

another. As in Experiment 1, the familiarization and test trials were each $8 \mathrm{~s}$ long, with a 2 second inter-trial interval.

\subsection{Results}

\subsubsection{Familiarization trials}

As in Experiment 1, we first examined the looking times during the familiarization trials in a mixed-design ANOVA for repeated measures with Gender, Age (for the infant participants) and Familiarization category (tight containment, loose containment) as the between-subjects factors and Trial (first 3, last 3 familiarization trials) as the within-subjects measure.

The results of the analysis on the infant data revealed a main effect for Familiarization trial, $F(1,18)=5.40, p<.05$. The infants looked reliably longer at the first 3 familiarization trials $(M=5.24 \mathrm{~s} ; S E=0.23)$ than the second 3 familiarization trials $(M=4.74 \mathrm{~s} ; S E=0.26)$. This decline in looking time suggests that these scenes appeared more similar to each other than was the case in Experiment 1. No further effects or interactions were found. The results for the adult participants showed no statistically significant effects or interactions. Adults tended to look as long to the first 3 familiarization trials $(M=7.19 \mathrm{~s} ; S E=.007)$ as to the second 3 familiarization trials $(M=7.22 \mathrm{~s} ; S E=.008)$. As the case with the adult data in Experiment 1, the adults in the present experiment followed instructions by looking at the pairs of scenes at close to ceiling level in every trial.

\subsubsection{Test trials}

To examine preferential looking during the test trials, a mixed-design ANOVA for repeated measures was conducted with Gender, Familiarization category and Age 
(for the infant data) as between-subject factors and Test trial and Scene as withinsubject factors. The results of the analysis conducted on the infant data showed a main effect for Scene, $F(1,18)=17.37, p=.001$. In contrast to the findings of the previous experiment (contrasting tight containment and loose support), infants at all ages preferred looking at the familiar $(M=3.41 \mathrm{~s} ; S E=0.29)$ to the novel scenes $(M=1.86 \mathrm{~s} ; S E=0.18)$. This finding was consistent across the three ages. No further effects or interactions were found.

Of interest is why these results show no developmental change such as found in Experiment 1. One possibility is that the contrast between types of containment (i.e., tight vs. loose) is a more subtle spatial category to parse. The consistent preference for the familiar over the novel scenes suggests that this may be the case. Infants may have been continuing to analyze the common spatial relation seen during the familiarization trials. Thus, they continued to look at the familiar relation during the test trials. Nevertheless, given that the preference for the familiar scenes was found regardless of the familiarization category, the response is categorical and not simply a preference for one of the test scenes.

The results of the analysis on the adult looking times showed no main effects or interactions. Looking to the novel test scenes (Test trial 1: $M=3.58 \mathrm{~s} ; S E=0.16$; Test trial 2: $M=3.66 \mathrm{~s} ; S E=0.19$ ) did not significantly differ from looking to the familiar test scenes (Test trial 1: $M=3.55 \mathrm{~s} ; S E=0.15$; Test trial $2: M=3.56 \mathrm{~s}$, $S E=0.19), F(1,28)=0.00, p=.99$. Thus, in contrast to the infant data, the looking data of the adults give no indication that the adult participants distinguished the tight- and loose-fitting containment relations.

\subsubsection{Proportion of participants who looked longer at the familiar test scenes}

In contrast to the previous findings in the infant data showing an increasing looking time to the novel scenes with age, the present experiment did not reveal such a pattern in the looking time analyses. Instead, a preference for looking at the familiar scene was found at all ages. At 9-months of age, $88 \%$ looked longer at the familiar test scenes, at 11-months and 14-months, 75 and 63\% looked longer at the familiar test scenes respectively.

For the adults, on the first test trial, exactly half of the participants looked longer at the novel than the familiar test scene and on the second test trial again exactly half of the participants looked longer at the novel test scene. Eight of the participants looked longer at the novel scene during both trials whereas the others did not. Of those participants who were familiarized with the loose containment relation $(N=16), 10(63 \%)$ of them looked longer overall at the novel (tight containment) relation. Of those participants who were familiarized with the tight containment relation $(N=16), 8(50 \%)$ looked longer overall to the novel (loose containment) relation. As found in the looking time data, no clear patterns of preference among the adult participants was found.

\subsubsection{Oddity task}

Correct selections (i.e., selections based on the distinction between tight and loose containment) were made by 12 of the 32 participants $(38 \%)$. A $\chi^{2}$ analysis was used 
to compare the number of correct responses with the chance expectation of 8 (based on the 32 participants who had a $25 \%$ chance of making a correct selection on the oddity task). The results were not significant, $\chi^{2}(1)=2.37$.

An examination of the explanations given by the 12 participants who made correct selections showed that only 7 of the 12 gave a correct rationale for their choice. These 7 participants mentioned degree of fit among the objects by using the terms "tight" and/or "loose" in their explanations. For example, one participant remarked on how the objects in loose-fitting relation just seemed to rattle around in their containers, but the other objects in the tight-fitting relation fit into the containers tightly. Two additional participants (both who were familiarized with the tight containment relation) chose correctly, but their explanation was a bit more vague. Their rationale was based on what they called either an unstable relation between the objects or that the object placed inside another could have been placed just anywhere (e.g., these objects were made to be used together whereas the others were not). The remaining 3 participants who made a correct selection on the oddity task based their selection on the color or texture of the objects (e.g., this one is made of foam or this one combines primary and pastel colors). The most frequent rationale given for incorrect selections pertained to the perceptual properties of the objects (e.g., this one is made out of a different material than the others).

\subsection{Discussion}

The results of this experiment show that by 9 months of age infants distinguish loose and tight fit within the category of containment. However, the results also contrasted with those found in Experiment 1. No shift in preference with development was found. Infants at all three ages showed a preference for the familiar over the novel test scenes. One possible explanation for the preference for the familiar scene is that this is a relatively difficult contrast to analyze. The differences in degree of fit across various containers may be less salient than the difference between tight-fitting containment and loose-fitting support tested in Experiment 1. An examination of the proportion data suggests that infants are becoming less sensitive to the contrast with age. Language acquisition is well underway by at least 14 months and it is possible that by this age infants are beginning to abstract the gist of how their language organizes space, even though as our previous research shows, they do not yet clearly understand these spatial terms (Choi et al., 1999). Also in contrast with Experiment 1, the adults in the present experiment did not show any indication of categorization of the spatial relations tested. No significant effects were found in their looking data and few were successful in choosing and describing the correct relation on the oddity task. These findings provide a further indication that this distinction is a subtle one for English-speaking adults.

\section{Experiment 3}

Our next question was whether infants raised in Korean-speaking environments and Korean-speaking adults would react differently to the tests used in Experiment 
2. Given that Korean spatial terms saliently mark the differences between tight and loose fit, it was expected that Korean adults would succeed on both the preferential looking task (by showing a preference during the test trials) and the oddity task by choosing and describing correctly the odd relation. Because infants presumably share the same cognitive abilities regardless of differences between the linguistic environments, we also expected that preverbal infants raised in Korean-speaking homes would categorize in much the same manner as those raised in English-speaking homes.

\subsection{Method}

\subsubsection{Participants}

Twelve infants who were all being raised in monolingual Korean-speaking homes participated in the present experiment. Four infants were 9-months of age $(M=9$ months, 18 days; range: 9 months, 4 days to 9 months, 29 days), four were 11months of age $(M=11$ months, 17 days; range: 11 months, 10 days to 11 months, 28 days) and the remaining four were 14-months of age $(M=14$ months, 19 days; range: 14 months, 7 days to 14 months, 27 days). All infants were recruited from families who had recently moved from Korea to Southern California. Korean immigrant/student families typically form rather closed communities and only Korean is spoken in the stores and churches within the community. In this way, much of Korean culture is preserved in the home setting. The infants were cared for solely by their parents and other family members who spoke only Korean in the home. Infants were given a small gift for participation.

Twenty, monolingual Korean-speaking adults also participated in this experiment. The Korean-speaking participants were recruited through personal contacts and through an ESL Institute for college students at San Diego State University. The Institute receives a large number of foreign students several times a year and provides ESL courses for up to a year. All Korean-speaking participants were recruited from among those who had come to the US within three months prior to the time of their participation. The instructions on the oddity task were as follows: "i neys cwung-eyse, etten-key nameci seys-hako talun-kayo?" (these four amongfrom, which-one three-with different-Polite?) which translates to "Among these four, which one is different from the other three?"

The same procedure used to test categorization of tight- vs. loose-fitting containment relations in Experiment 2 was used in the present experiment. Half of the participants within each age were familiarized with the tight fitting containment relation and the remaining half were familiarized with the loose fitting containment relation. All participants received the same test pairs.

\subsection{Results}

\subsubsection{Familiarization trials}

The results of the repeated measures ANOVA with Trial (first 3, last 3 familiarization trials) as the within-subjects factor and Age (for the infants) and Familiariza- 
tion category as the between-subjects factors showed a main effect for Trial, $F(1,6)=6.19, p<.05$. Infant looking time during the first 3 familiarization trials $(M=6.93 \mathrm{~s} ; S E=0.85)$ was significantly greater than the last 3-familiarization trials $(M=6.41 \mathrm{~s} ; S E=0.74)$, thus suggesting that the scenes appeared similar during their second presentation. A comparison between the infants raised in Koreanspeaking homes in the present experiment and the infants raised in English-speaking homes in Experiment 2, in which the same contrast was tested, shows that the infants raised in Korean speaking homes attended to the stimuli on the familiarization trials longer, $\mathrm{F}(1,40)=19.99, p<.01$ (6.67 vs. 4.99 s).

The looking time during familiarization trials for the Korean-speaking adults showed no significant findings. Looking during the first 3 trials $(M=6.89 \mathrm{~s}$; $S E=0.10)$ did not differ significantly from the looking time during the last 3 trials $(M=6.97 \mathrm{~s} ; S E=.006), F(1,18)=0.82, p=0.38$. Note that like the data from the English-speaking adults, these looking times approach ceiling (Maximum $=8 \mathrm{~s}$ ) indicating that the participants followed the directions to look at the scenes, even those they had seen before.

\subsubsection{Test trials}

We next examined the test trial data for categorization of the tight and loose containment relations. An examination of the infant data showed that during the second test trial, 5 of the infants did not look at the novel scene at all and 1 looked less than $0.10 \mathrm{~s}$ at the novel scene. Nonlooking at the novel scene during the second test trial was found equally often at each age ( 2 at each age). Given that a preferential looking task is based on the assumption that infants look at both scenes and make a choice as to what they prefer to examine, it was decided to analyze the data from the first test trial only. As in previous experiments, a mixed-design ANOVA for repeated measures was conducted with Age and Familiarization category as the between-subjects factors and Scene (Novel, Familiar) as the within-subjects factor.

As can be seen in Fig. 4, a main effect was found for Scene, $F(1,6)=10.18$, $p<.05$. Infants looked significantly longer at the familiar $(M=4.68 \mathrm{~s} ; S E=1.99)$ than the novel scenes $(M=2.47 \mathrm{~s} ; S E=1.14)$. This effect was not qualified by familiarization category or age. Thus, the preference shown was due to a categorical response rather than a preference for a particular test scene. Also shown in Fig. 4 are the infant data from Experiment 2, showing the same looking preferences as the infants in the present experiment.

The results of the analysis on the adults showed a main effect for Scene, $F(1,18)=30.22, p<.001$. In contrast to the results from the English-speaking adults, but consistent with the results from infants raised in English-speaking and Korean-speaking homes, the Korean-speaking adults looked significantly longer at the familiar $(M=4.51 \mathrm{~s} ; S E=0.22)$ than the novel test scenes $(M=2.29 \mathrm{~s}$; $S E=0.20)$. No further effects or interactions were found. For comparison purposes, the adult data from Experiment 2 are presented along with the adult data from this experiment in Fig. 4 showing the contrasting results between the two language groups. 


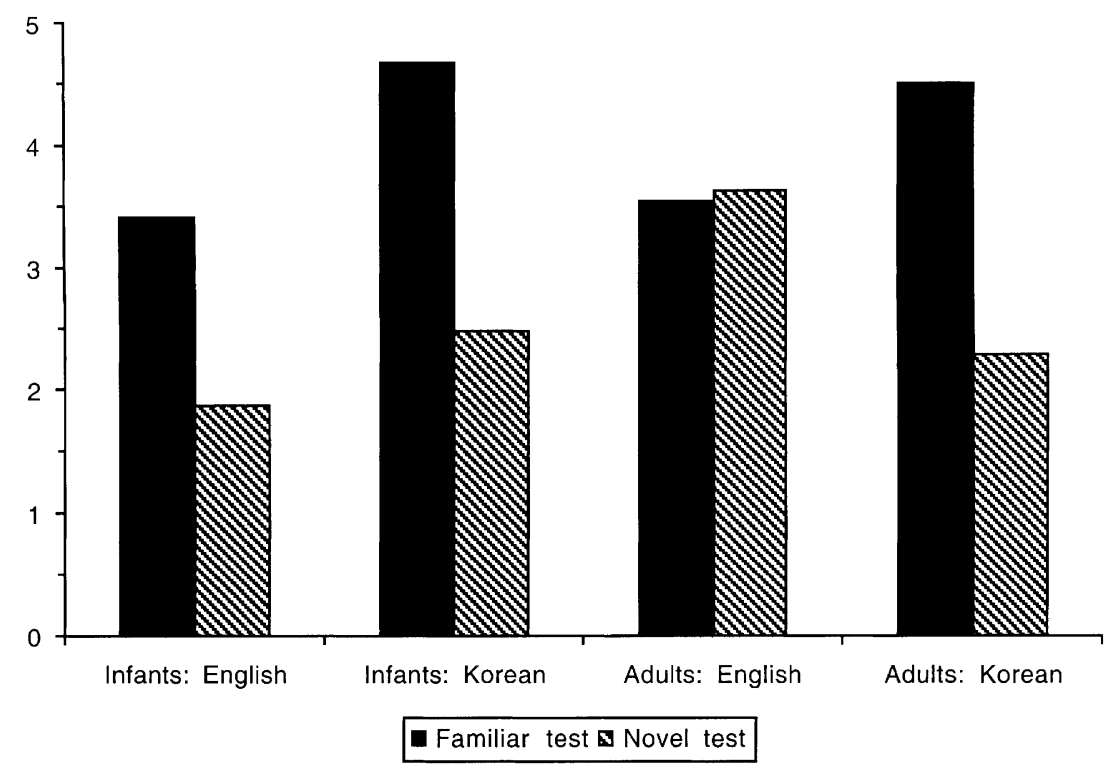

Fig. 4. Results from Experiments 2 and 3 showing both the infant data (infants raised in English-speaking homes and infants raised in Korean speaking homes) and adult data (English and Korean speakers).

\subsubsection{Proportion of participants who looked longer at the familiar test scenes}

Very few infants preferred to look at the novel scenes in either the first or second test trial. Nine of the 12 infants $(75 \%)$ looked longer at the familiar scene in the first test trial and 9 infants $(75 \%)$ looked longer at the familiar scene during the second test trial (but 6 of the 9 did not look at the novel scene at all). Thus, the data are similar to the findings with infants raised in English-speaking homes. In sharp contrast to the English-speaking adult data, 19 of the 20 Korean-speaking adults (95\%) looked longer at the familiar than the novel test stimuli.

\subsubsection{Oddity task}

Sixteen of the participants $(80 \%)$ made a correct choice on the oddity task, a rate greater than expected by chance alone, $\chi^{2}(1)=22.50, p<.001$. Of the 19 participants who looked at the familiar stimuli longer than the novel ones, 16 of them (84\%) chose correctly on the oddity task. We also examined the kinds of verbal reports given as explanations for the choices made. Four of the adults ( 3 who looked longer at the familiar scene and the 1 participant who did not) gave answers that did not describe the relations as tight- or loose-fitting containment. Two participants chose the object set in which the items were placed inside using a vertical motion, which can also be described in Korean as "kkocta" which is a correct description, just not the one we were looking for. One participant did not give an explanation and the other described the cork in the bottle as an "on top of" relation. Note that in contrast to the English-speaking adults, none of the Korean-speaking adults made 
choices based on the properties of the objects themselves. All explanations were given according to a spatial relation.

\subsection{Discussion}

Infants raised in Korean-speaking homes showed the same pattern of categorization of tight- vs. loose-fitting containment relations as infants raised in Englishspeaking homes: both groups looked longer at the familiar than the novel relations during the test trials. These results suggest that preverbal infants' categorization of tight and loose fit containment may be universal. The results of the analyses from the adults in the two experiments strongly contrasted with each other. Unlike English-speaking adults, Korean-speaking adults categorized the tight and loose fitting containment relations as shown in the preferential looking to the familiar test scenes as well as in their correct choices and explanations in the oddity task. Most Englishspeaking adults did not describe such a distinction. Instead, they focused primarily on the perceptual properties of the objects in Experiment 2 whereas they focused more on the relations in Experiment 1. The results suggest that a developmental change in flexibility occurs either during language acquisition early in development or with expertise in the use of language which occurs later in development.

\section{Comparison analyses}

In order to contrast further the results of the infants and adults in Experiments 2 and 3, we conducted two crossexperiment analyses to see if there were any interactions that would qualify our conclusions. In each of the analyses, the mean of test trials one and two was calculated and the mean looking time to the novel and familiar scenes was entered as the dependent measure. First, we analyzed the infant data by placing all the infants from Experiments 2 and 3 in one analysis and examined for differences due to their different linguistic environments. The results showed that the infants raised in Korean environments looked longer at both the scenes overall $(M=3.83)$ than those raised in English-speaking environments $(M=2.67), F(1,36)=25.48, p<.001$, which is evident in Fig. 4. The results also showed a main effect for Scene, $F(1,36)=26.27, p<.001$ showing that infants looked longer overall at the familiar $(M=3.91)$ than the novel test scenes $(M=2.11)$; however, the interaction involving Scene and Language was not significant, $(p=.13)$ showing that both groups showed the same looking preferences. That is, prior to learning spatial terms, infants from different cultures and linguistic environments distinguish tight- and loose-fitting containment relations. Second, we compared the results of the English-speaking adults in Experiment 2 and the Korean-speaking adults in Experiment 3 to make sure that the two groups significantly differed in their looking preferences. As expected, an interaction between Scene and Language was found, $F(1,50)=28.76, p<.001$. As reported in Experiment 2, the English-speaking adults showed no looking preferences (Familiar $M=3.55$; Novel $M=3.62$ ) and the Korean-speaking adults looked significantly longer at the familiar than the novel scenes (4.51 vs. 2.30). 
We then compared the infant and adult looking patterns in Experiment 2. Given that no significant differences were found among the different ages of the infants, the Age factor in this analysis was defined as infant or adult. An interaction was found involving Scene and Age, $F(1,60)=12.02, p<.001$. As reported in Experiment 2, the infants showed preferences for the familiar test scenes and the English-speaking adults showed no preferences. These comparisons provide further statistical support for the conclusions made in the individual experiments.

\section{General discussion}

In these experiments a preferential-looking technique was used to study how both infants and adults categorize spatial relations. The advantage of the preferential looking technique is that the same stimuli, presentation and dependent measure can be used with these widely varying populations. The stimuli were filmed events of dynamic spatial relations being demonstrated with widely varying objects. Because looking preferences to nonverbal stimuli rather than verbal responses were examined, we could compare categorization abilities before and after language is acquired. To investigate further the influence of language on spatial representation, an oddity task was used which provided additional information as to how adults construe scenes such as those shown in the preferential looking task.

The results add to the growing body of data showing that infants conceptualize containment and support relations well before language is acquired (Aguiar \& Baillargeon, 1998; Baillargeon, 1994; Needham \& Baillargeon, 1993). In the prior research looking times to possible and impossible events were measured and the data showed that in similar contexts infants distinguish containment from noncontainment and support from nonsupport. In this kind of research, infants only need to detect a change in a criterial feature of containment or support in the same or highly similar objects across trials. The present study adds to these findings by showing that infants can abstract spatial relations even in noisy arrays in which the scenes change in terms of the shapes, textures and sizes of the objects as well as the number of objects used to demonstrate the relation. Infants can focus on highly complex relations such as tight-fitting containment and loose-fitting support as well as relations within a containment category, namely tight and loose fit. They can categorize these relations during the preverbal period, thus giving them a starting place from which linguistic terms (whether English or Korean) can be learned in a meaningful way.

A comparison between the infants raised in English-speaking and those raised in Korean-speaking homes showed no differences; both showed the same looking preferences and the same percentage $(75 \%)$ of infants in each home setting contributed to this finding. Yet, the experiences they will have once they begin learning language will differ. Those learning English will group the tight- and loose-fitting containment relations into a single category, one labeled by the term "in." Later in development, they will learn the terms "loose" and "tight" but the latter terms are not highlighted in English to the same extent as "in" and "on"; nor are they part of the obligatory 
lexicon when talking about containment or support. The infants who will grow up learning Korean will continue to distinguish between the tight- and loose-fitting containment categories, as they are subsets of the spatial terms "kkita" ('tight fit or interlock') and "nehta" ('put in or around loosely') respectively. They will also learn that their language makes further distinctions that either have been already learned preverbally or else will be learned with the aid of linguistic input. For example, in the production data collected by Bowerman and Choi (1994), young children's semantic spatial categories were larger and less differentiated than those of adults. This finding was consistent for both English- and Korean-speakers. Whether this result is attributable to children's smaller vocabulary size or their larger conceptual groupings of spatial relations is unknown. Further research with preverbal infants should help illuminate the answer to this question.

The results from the adult data support the view that the language we learn can influence thought (e.g., Boroditsky, 2001; Levinson, 1996; Lucy, 1992; Lucy \& Gaskins, 2000; Whorf, 1956), particularly in our initial construal of scenes. In Experiment 1, the English-speaking adults showed categorization of tight-fitting containment and loose-fitting support in both the preferential looking and oddity tasks. However, their descriptions were focused on containment ("in") and support ("on") with no mention of the degree to which fit was involved with either relation. In Experiment 2, which tested tight- and loose-fitting containment, they had difficulties with both tasks. One possibility is that all the scenes depicted containment and this relation was so salient through their exposure to and use of the English lexical and morphological systems that it obscured the differences between the tight and loose fit. A few adults verbalized the distinction, but most reports showed they focused on the perceptual properties of the objects. ${ }^{2}$ In contrast, none of the Korean-speaking adults in Experiment 3 offered an explanation in terms of object properties. The contrasting relation between what can be described as the difference between "kkita" ('tight fit or interlock') and "nehta" ('loose in or around') was highly salient to them. The few errors made on the oddity task were based on other relations, namely "kkocta" ("the placement of a solid and typically elongated object into a container/ground with a vertical motion', such as putting pencils/pens into a pencil cup or putting a flag pole into the ground) and "tamta" ("putting multiple objects into a single container', such as placing several blocks into a cloth bag). Although "nehta" could have been used to describe these relations, "kkocta" and "tamta" are more precise descriptions.

An interesting question is why the English-speaking adults focused more on the object properties. Descriptions based on the perceptual properties of objects were prevalent in Experiment 2 but were also found (albeit to a lesser degree) in Experiment 1 . One answer could be that languages differ in the extent to which the properties of objects are specified in their relational terms (e.g., prepositions/par-

\footnotetext{
${ }^{2}$ It should be pointed out that in the oddity task, any selection based on the objects' properties was incorrect: the four object groups differed sufficiently in shape, color, size, and material so that no item could be singled out as an odd one.
} 
ticles, predicates, verbs). Spatial terms in English, such as "in" and "on," do not refer to the specific properties of objects, only more general ones. For example, the form of an object must have some degree of concavity in order to provide containment (for the term "in"). Nevertheless, relative to the definitions of English spatial terms, spatial terms in Korean make more specifications about the shape, material and orientation of objects that are involved in a relation (e.g., "kkocta") or the number of objects involved in a relation (e.g, "tamta"). Furthermore, in languages such as Korean, the meaning of a spatial term can highlight the contours of the objects placed in relation to each other (e.g., "kkita"). The Tzeltal language provides another example. In Tzeltal, different locative predicates are used depending on the shape of the container, orientation, material, shape, and animacy of the figure object, as well as the quantity of the figure object(s) (Brown, 1994). Spatial terms that are general to most objects (such as those in English) may less likely be accessed if the participant is more narrowly focused on object properties; whereas spatial terms that highlight the object properties (such as those in Korean) may more likely be accessed even though the observer may also be focusing on the object properties. The data show some support for this view in that only $69 \%$ of the English-speaking adults categorized tight fitting containment vs. loose fitting support (a contrast of 'in' vs. 'on') whereas $95 \%$ of the Korean-speaking adults categorized tight fitting vs. loose fitting containment (a contrast between 'kkita' and 'nehta').

It is interesting to note that the different foci of attention shown by English and Korean speakers (English speakers toward object properties and Korean speakers toward relational properties) parallels crosslinguistic differences reported by Choi and Gopnik (1995); (see also Choi, 2000) on early lexical development. Whereas English-learning children focus primarily on acquiring nominal words (i.e., nouns), Korean children acquire many relational words (i.e., verbs and other predicate words).

It may also be that the saliency of spatial relations vis a vis object properties changes from infancy to adulthood. The data from the present experiments suggest that the preverbal infant is more flexible and open in parsing dynamic events. That is, in contrast to traditional views on the categorization abilities of infants, the data show that infants can ignore the forms of various objects and focus instead on the relations being demonstrated. They can also ignore the perceptual differences among objects and categorize them based on their relations with other objects (e.g., they generalize behavior across domains that vary widely in their structure, such as animals and vehicles; Mandler \& McDonough, 1998). Adults, however, are less flexible in that they can have difficulties ignoring object properties when the spatial relations are not those commonly used in the language they speak. In all three experiments, we have evidence for a flexible infant who can categorize various relations across a wide array of objects; evidence for a less flexible but more lexical adult is also found, particularly in the comparison of the results from Experiments 2 and 3 .

The results also showed differences in looking preferences across the three experiments. In Experiment 1, a preference for the novel scene was found for the older 
infants and the adults whereas the youngest infants preferred the familiar scene. In Experiments 2 and 3, a preference was found for the familiar scene for all the infants and the Korean-speaking adults. A possible reason for these developmental and task differences is that more complex stimuli require more time to process. In their research on infant looking preferences, Hunter et al. (1983) showed that when processing of the familiarization stimuli is ongoing during test trials, then a preference for the familiar scene is found. However, if the stimuli are less complex, then processing would be complete by the time the test trials are administered and infants would be more motivated to move their focus to the novel scene (see also Reznick \& Kagan, 1983). Given that the preferential-looking task was originally designed to test infants, the kind of systematic research conducted by Hunter and his colleagues has not been conducted with adults.

It should be pointed out that we did not require habituation of the familiarization stimuli of either our infant or adult participants. Although infant looking decreased significantly from the first 3 to the second 3 familiarization trials in Experiments 2 and 3 , the decrease was not within the typical requirements of habituation, which is a $50 \%$ criterion decrease in looking from the first to the last block of familiarization trials. The small decrease in the present experiments was likely due to the fact that the second 3 familiarization trials were identical to the first (but presented on opposite screens) and the infants remembered seeing them. Given that we used highly varied scenes of dynamic rather than static stimuli and gave infants so few exposures to them, categorization would be unlikely to occur in the context of the experiment. It seems plausible that the categorizations the infants made were based on prior experience rather than being formed de novo during the brief course of the experiment.

In Experiment 1, the contrasting relations were conflated in that they could be distinguished on two bases: containment vs. support or tight vs. loose fit. Either approach would result in successful discrimination. It is likely that the older infants were sensitive to the containment/support and/or the fittingness relations; they looked longer at the novel scene. However, the youngest infants may still have been processing the scenes, suggesting that they were not picking up on the relations as quickly as the older infants were. It is also possible that the youngest infants may have been attending to the tight and loose fit aspect of the relations; thus, they looked longer at the familiar relation just as they did when this distinction was tested in Experiments 2 and 3. In Experiments 2 and 3, the infants and the Korean-speaking adults all looked longer at the familiar scene. We have suggested that the distinction between tight and loose fit (particularly in the context of the same spatial relation, namely containment) is more subtle. Thus, the infants may have taken longer to process these relations. However, this distinction was probably not subtle for Korean-speaking adults. After all, 'kind of fit' is obligatory in Korean spatial terms. In English we can talk about spatial relations without mentioning fit, but this is not true of Korean. Given that spatial relations are discussed in both languages, the tight/loose distinction must be more frequent in Korean than in English because it is not grammatically optional. Unfortunately there are no corpus frequencies for Korean, so a more precise comparison is not possible. 
The preference for the familiar test scene by Korean-speaking adults is likely due to the need to overlook some of the finer distinctions made in their language (e.g., "kkocta" and "tamta") in order to determine the categorical differences. It is also likely that the reason for longer looking at the familiar scene by the adults is different from the reason why infants looked longer at the familiar scene. Whereas the infants do not have language to guide their categorization, the adults have finer linguistic distinctions that may have influenced their categorization strategies in the task.

Our experiments suggest that the difference between tight and loose containment is salient around 9 months of age but becomes less salient as English speakers learn their semantic system. Our data more generally indicate that once children acquire the semantic system of their own language, their nonlinguistic sensitivity to those distinctions not made in their language diminishes over time. There appear to be similarities between the loss in sensitivity to tight versus loose fitting aspects of containment by English speakers shown in Experiment 2 and the loss of phonetic contrasts that are not phonemic in one's native tongue (Kuhl, Williams, Lacerda, Stevens, \& Lindblom, 1992; Werker \& Lalonde, 1988). But there are many differences between the perceptual tuning of the sounds of one's language and the conceptual tuning of semantic categories that result from what the language emphasizes. It may be premature at this stage of research to attempt such an equation.

The present study shows that at least by 9-months of age, infants have developed spatial concepts that they use to comprehend the language they hear. It is possible that the set of primitive concepts is reasonably large and may be the basis for the notion of semantic primitives that has been used in the linguistic literature to account for commonalities among relational terms across languages. However, the present study cannot tell us how preverbal categories become coordinated with semantic categories. We tested only a few of many different types of distinctions made in the languages of the world (Ameka, 1995; Bowerman \& Choi, 2001; Bowerman, Choi, \& de Leon, 1995; Brown, 1994; Levinson, 1996), so we do not know how extensive preverbal spatial categories are. The categories we studied here are not lexicalized in either Korean or English as full-fledged semantic categories, but are subevents of the semantic categories of the two languages. For example, 'tight in' is a subset of the "kkita" category, which also refers to placing tightly in, on, around, and together. It is still an open question as to whether the full semantic category of "kkita" is established prelinguistically or whether it requires further combination of concepts. Children must attend to and process the linguistic input in order to either identify the relevant concepts among possible ones or to construct the needed semantic category from the available stock of preverbal concepts. Thus, both language and preverbal conceptual readiness play important roles in developing language-specific semantic categories of space. Clearly, more research is needed with preverbal infants as well as with children with differing levels of linguistic expertise in order to address further the issue of how semantic categories are acquired and when language begins to influence categorization of spatial relations. 


\section{Acknowledgments}

This research was made possible by NSF Grant 9973399 to Laraine McDonough, NSF Grant 970895 to Jean Mandler and Laraine McDonough. We would like to thank Melissa Bowerman who stimulated our thinking on the relationship between thought and language. We also appreciate the assistance of Lisa Hoag, Laura Holmes and several undergraduate students at UCSD for all their help without which this work would not be possible.

\section{Appendix A}

The order of presentation of the scenes used in Experiments 1, 2, and 3 (descriptions of scenes below). Test scenes were counterbalanced across participants. For example, on Test 1 , the Novel test scene was on the left monitor for half the participants and on the right monitor for the other half.

\begin{tabular}{lll}
\hline Trial & Left monitor & Right monitor \\
\hline 1 & Scene 1 & Scene 2 \\
2 & Scene 3 & Scene 4 \\
3 & Scene 5 & Scene 6 \\
4 & Scene 2 & Scene 1 \\
5 & Scene 4 & Scene 3 \\
6 & Scene 6 & Scene 5 \\
Test 1 & Novel test scene & Familiar test scene \\
Test 2 & Familiar test scene & Novel test scene \\
\hline
\end{tabular}

A description of the stimuli used to demonstrate the relations in the familiarization and test trials for each experiment.

Experiment 1

The familiarization scenes showing demonstrations of loose-fitting support relations

\begin{tabular}{ll}
\hline 1 & 3 round unpainted wooden pegs placed on a single large rectangular unpainted wooden board \\
2 & 3 bean-bag frogs of different colors and patterns placed on 3 sheets of paper \\
3 & 3 differently shaped and colored cups/mugs placed on a single table \\
4 & 3 differently shaped and colored triangles balanced on top of 3 long thin rectangles standing on end \\
(each a different color)
\end{tabular}




\begin{tabular}{|c|c|c|}
\hline \multicolumn{3}{|c|}{$\begin{array}{l}\text { Test trials for Experiment } 1 \\
\text { Right scene }\end{array}$} \\
\hline \multicolumn{2}{|c|}{$\begin{array}{l}3 \text { pastel colored, foam letters }(\mathrm{S}, \mathrm{E}, \mathrm{T}) \\
\text { of various colors placed standing up } \\
\text { on a flat surface }\end{array}$} & $\begin{array}{l}3 \text { foam letters }(\mathrm{S}, \mathrm{E}, \mathrm{T}) \text { of various colors placed in } \\
\text { appropriately shaped cut-out sections in } 3 \text { mats }\end{array}$ \\
\hline \multicolumn{2}{|c|}{$\begin{array}{l}\text { Wooden dowels painted different } \\
\text { primary colors placed in the holes } \\
\text { of plastic shapes of different colors }\end{array}$} & $\begin{array}{l}\text { Plastic shapes of different colors placed one on top } \\
\text { of the other }\end{array}$ \\
\hline \multicolumn{3}{|c|}{$\begin{array}{c}\text { Experiments } 2 \text { and } 3 \\
\text { The familiarization trials showing demonstrations of loose-fitting containment relations }\end{array}$} \\
\hline 1 & \multicolumn{2}{|c|}{$\begin{array}{l}3 \text { different geometric shapes (neon pink, blue, and green) placed into oval, cloth-covered, beige } \\
\text { jewelry boxes }\end{array}$} \\
\hline 2 & \multicolumn{2}{|c|}{$\begin{array}{l}3 \text { pencils/pens placed inside an pencil cup with an olive green upper portion and wood textured } \\
\text { bottom portion }\end{array}$} \\
\hline & \multicolumn{2}{|c|}{3 differently colored bristle blocks placed in a beige cloth sack } \\
\hline & \multicolumn{2}{|c|}{$\begin{array}{l}3 \text { geometric wooden blocks (different primary colors) placed in a light blue, rectangle shaped, } \\
\text { plastic basket }\end{array}$} \\
\hline & \multicolumn{2}{|c|}{3 lego persons placed in the large compartment located on a dump truck. } \\
\hline & \multicolumn{2}{|c|}{$\begin{array}{l}\text { Small, rubber, 3-dimensional asterisks of different neon colors placed in differently shaped cooking } \\
\text { tins }\end{array}$} \\
\hline \multicolumn{3}{|c|}{ The familiarization trials showing demonstrations of tight-fitting containment relations } \\
\hline & \multicolumn{2}{|c|}{$\begin{array}{l}3 \text { different geometric shapes (neon pink, blue and green) placed in the top section of a yellow form } \\
\text { box (used to teach infants shapes) }\end{array}$} \\
\hline & \multicolumn{2}{|c|}{3 pastel colored keys placed in keyholes located in two sides of a single yellow box } \\
\hline & \multicolumn{2}{|c|}{$\begin{array}{l}3 \text { corks (such a used in wine bottles) placed in } 3 \text { semi-transparent bottles ( } 1 \text { clear, } 1 \text { violet, and } 1 \\
\text { green). }\end{array}$} \\
\hline & \multirow{2}{*}{\multicolumn{2}{|c|}{$\begin{array}{l}4 \text { stacking cups (each a different primary color), placed one at a time inside of the } n \\
3 \text { lego persons placed in } 3 \text { different kinds of lego cars (all different primary colors) }\end{array}$}} \\
\hline & & \\
\hline & \multicolumn{2}{|c|}{$\begin{array}{l}3 \text { different sized children's books with varied designs on them placed into } 3 \text { brightly colored covers } \\
\text { (different primary colors) designed to contain the books }\end{array}$} \\
\hline
\end{tabular}

Test trials for Experiments 2 and 3

Left scene Right scene

3 pastel colored, foam letters (S, E, T) of various 3 foam letters $(S, E, T)$ of various colors placed in colors placed in bowls appropriately shaped cut-out sections in 3 mats

Wooden dowels painted different primary colors placed in the holes of plastic shapes of different Wooden dowels placed inside various, rectangular colors

\section{References}

Aguiar, A., \& Baillargeon, R. (1998). Eight-and-a-half-month-old infants' reasoning about containment events. Child Development, 69, 636-653.

Ameka, F. (1995). The linguistic construction of space in Ewe. Cognitive Linguistics, 6, 139-181.

Au, T. K.-F. (1992). Counterfactual reasoning. In G. R. Semin, \& K. Fiedler (Eds.), Language, interaction and social cognition (pp. 194-213). Thousand Oaks, CA: Sage Publications. 
Baillargeon, R. (1994). How do infants learn about the physical world? Current Directions in Psychological Science, 3, 133-140.

Baillargeon, R. (1995). A model of physical reasoning in infancy. In C. Rovee-Collier, \& L. P. Lipsitt (Eds.), Advances in infancy research: Vol. 9 (pp. 305-371). Norwood, NJ: Ablex.

Bierwisch, M. (1967). Some semantic universals of German adjectivals. Foundation of Language, 3, 1-36.

Bloom, A. H. (1981). The linguistic shaping of thought: A study in the impact of language on thinking in China and the west. Hillsdale, NJ: Erlbaum.

Bloom, L., Lifter, K., \& Broughton, J. (1985). The convergence of early cognition and language in the second year of life: Problems in conceptualization and measurement. In M. Barrett (Ed.), Children's single-word speech (pp. 149-180). New York: Wiley.

Boroditsky, L. (2001). Does language shape thought? Mandarin and English speakers' conceptions of time. Cognitive Psychology, 43, 1-22.

Bowerman, M. (1989). Learning a semantic system: What role do cognitive predispositions play? In M. L. Rice, \& R. L. Schiefelbusch (Eds.), The teachability of language (pp. 133-169). Baltimore: Brookes.

Bowerman, M. (1996a). The origins of children's spatial semantic categories. In J. J. Gumperz, \& S. C. Levinson (Eds.), Rethinking linguistic relativity (pp. 145-176). New York: Cambridge University Press.

Bowerman, M. (1996b). Learning how to structure space for language: A crosslinguistic perspective. In P. Bloom, M. Peterson, L. Nadel, \& M. Garrett (Eds.), Language and space (pp. 385-486). Cambridge, MA: MIT Press.

Bowerman, M. \& Choi, S. (1994). Linguistic and nonlinguistic determinants of spatial semantic development. Paper presented at the Boston University Conference on Language Development, January.

Bowerman, M., \& Choi, S. (2001). Shaping meanings for language: Universal and language-specific in the acquisition of spatial semantic categories. In M. Bowerman, \& S. C. Levinson (Eds.), Language acquisition and conceptual development (pp. 475-511). Cambridge: Cambridge University Press.

Bowerman, M., Choi, S., \& de Leon, L. (1995). Verbs, particles, and spatial semantics: Learning to talk about spatial actions in typologically different languages. In E. Clark (Ed.), The proceedings of the 27th annual child language research forum (pp. 101-110). Stanford: Center for the Study of Language and Information.

Brown, P. (1994). The Ins and Ons of Tzeltal locative expressions: The semantics of static descriptions of location. Linguistics, 32, 743-790.

Brown, R. (1973). A first language: The early stages. Cambridge, MA: Harvard University Press.

Carey, S. (1982). Semantic development: The state of the art. In E. Wanner, \& L. Gelitman (Eds.), Language acquisition: The state of the art (pp. 264-293). Cambridge, MA: MIT Press.

Choi, S. (2000). Caregiver input in English and Korean: Use of nouns and verbs in book-reading and toyplay contexts. Journal of Child Language, 27, 69-96.

Choi, S., \& Bowerman, M. (1991). Learning to express motion events in English and Korean: The influence of language-specific lexicalization patterns. Cognition, 41, 83-121.

Choi, S., \& Gopnik, A. (1995). Early acquisition of verbs in Korean. Journal of Child Language, 22, 297 331.

Choi, S., McDonough, L., Bowerman, M., \& Mandler, J. M. (1999). Early sensitivity to language-specific spatial categories in English and Korean. Cognitive Development, 14, 241-268.

Clark, E. V. (1973). What's in a word? On the child's acquisition of semantics in his first language. In T. E. Moore (Ed.), Cognitive development and the acquisition of language (pp. 65-110). New York: Academic Press.

Clark, H. H. (1973). Space, time, semantics, and the child. In T. E. Moore (Ed.), Cognitive development and the acquisition of language (pp. 27-63). New York: Academic Press.

Emmorey, K. (1996). The confluence of space and language in signed languages. In P. Bloom, M. A. Peterson, L. Nadel, \& M. F. Garrett (Eds.), Language and space (pp. 171-210). Cambridge, MA: MIT Press.

Hunter, M. A., Ames, E. W., \& Koopman, R. (1983). Effects of stimulus complexity and familiarization time on infant preferences for novel and familiar stimuli. Developmental Psychology, 19, 338-353.

Johnson, M. (1987). The body in the mind: The bodily basis of meaning, imagination, and reasoning. Chicago: University of Chicago Press. 
Johnson, S., Slaughter, V., \& Carey, S. (1998). Whose gaze will infants follow: The elicitation of gazefollowing in 12-month-olds. Developmental Science, 1, 233-238.

Keppel, G. (1982). Design and analysis: A researcher's handbook (2nd ed). Englewood Cliff, NJ: Prentice Hall.

Kuhl, P. K., Williams, K. A., Lacerda, F., Stevens, K. N., \& Lindblom, B. (1992). Linguistic experience alters phonetic perception in infants by 6 months of age. Science, 255, 606-608.

Lakoff, G. (1987). Women, fire, and dangerous things: What categories reveal about the mind. Chicago: University of Chicago Press.

Legerstee, M. (1992). A review of the animate-inanimate distinction in infancy: Implications for models of social and cognitive knowing. Early Development and Parenting, 1, 59-67.

Levelt, W. J. M. (1996). Perspective taking and ellipsis in spatial descriptions. In P. Bloom, M. A. Peterson, L. Nadel, \& M. F. Garrett (Eds.), Language and space (pp. 77-108). Cambridge, MA: MIT Press.

Levinson, S. C. (1996). Relativity in spatial conception and description. In J. J. Gumperz, \& S. C. Levinson (Eds.), Rethinking linguistic relativity (pp. 177-202). New York: Cambridge University Press.

Lucy, J. A. (1992). Language diversity and thought: A reformulation of the linguistic relativity hypothesis. New York: Cambridge University Press.

Lucy, J., \& Gaskins, S. (2000). Grammatical categories and the development of classification preferences: A comparative approach. In M. Bowerman, \& S. C. Levinson (Eds.), Language acquisition and conceptual development (pp. 257-283). Cambridge: Cambridge University Press.

Mandler, J. M. (1992). How to build a baby: II. Conceptual primitives. Psychological Review, 99, 587604.

Mandler, J. M. (1996). Preverbal representation and language. In P. Bloom, M. Peterson, L. Nadel, \& M. Garrett (Eds.), Language and space (pp. 365-384). Cambridge, MA: MIT Press.

Mandler, J. M., \& McDonough, L. (1996). Drinking and driving don't mix: Inductive generalization in infancy. Cognition, 59, 307-335.

Mandler, J. M., \& McDonough, L. (1998). On developing a knowledge base in infancy. Developmental Psychology, 34, 1274-1288.

Mandler, J. M., \& McDonough, L. (2000). Advancing downward to the basic level. Journal of Cognition and Development, 1, 379-403.

McDonough, L., \& Mandler, J. M. (1998). Inductive generalization in 9- and 11-month olds. Developmental Science, 1, 227-232.

Naigles, L. (1990). Children use syntax to learn verb meanings. Journal of Child Language, 17, 357-374.

Needham, A., \& Baillargeon, R. (1993). Intuitions about support in 4.5-month-old infants. Cognition, 47, $121-148$.

Nelson, K. (1974). Concept, word, and sentence: Interrelations in acquisition and development. Psychological Review, 81, 267-285.

Nelson, K., \& Lucariello, J. (1985). The development of meaning in first words. In M. Barrett (Ed.), Children's single-word speech. New York: Norton.

Pederson, E., Danziger, E., Levinson, S., Kita, S., Senft, G., \& Wilkins, D. (1998). Semantic typology and spatial conceptualisation. Language, 74, 557-589.

Quinn, P. C. (1999). Development of recognition and categorization of objects and their spatial relations in young infants. In L. Balter, \& C. S. Tamis-LeMonde (Eds.), Child psychology: A handbook of contemporary issues (pp. 85-115). Philadelphia, PA: Psychology Press/Taylor and Francis.

Quinn, P. C., Cummins, M., Kase, J., Maartin, E., \& Weissman, S. (1996). Development of categorical representations for above and below spatial relations in 3- to 7-month-old infants. Developmental Psychology, 32, 942-950.

Reznick, J. S., \& Kagan, J. (1983). Category detection in infancy. Advances in Infancy Research, 2, 79-111.

Sinha, C., Thorseng, L. A., Hayashi, M., \& Plunkett, K. (1994). Comparative spatial semantics and language acquisition: Evidence from Danish, English, and Japanese. Journal of Semantics, 11, 253-287.

Slobin, D. I. (1973). Cognitive prerequisites for the development of grammar. In C. A. Ferguson, \& D. I. Slobin (Eds.), Studies of child language development (pp. 175-208). New York: Holt, Rinehart \& Winston. 
Slobin, D. I. (1985). Crosslinguistic evidence for the language-making capacity. In D. I. Slobin (Ed.), The crosslinguistic study of language acquisition. Vol. 2: Theoretical issues (pp. 1157-1256). Hillsdale, NJ: Erlbaum.

Slobin, D. I. (1996). From "thought and language" to "thinking for speaking". In J. J. Gumperz, \& S. C. Levinson (Eds.), Rethinking linguistic relativity (pp. 70-96). New York, NY: Cambridge University Press.

Spelke, E. S., Phillips, A., \& Woodward, A. L. (1995). Infants' knowledge of object motion and human action. In D. Sperber, D. Premack, \& A. J. Premack (Eds.), Causal cognition (pp. 44-78). Oxford: Oxford University Press.

Talmy, L. (1985). Lexicalization patterns: Semantic structure in lexical forms. In T. Shopen (Ed.), Language typology and syntactic description: Vol. 3 Grammatical categories and the lexicon (pp. 57149). Cambridge, UK: Cambridge University Press.

Werker, J., \& Lalonde, C. E. (1988). Cross-language speech perception: Initial capabilities and developmental change. Developmental Psychology, 24, 672-683.

Whorf, B. (1956). In J. B. Carroll (Ed.), Language, thought, and reality: Selected writings of Benjamin Lee Whorf. Cambridge, MA: MIT Press. 